\title{
Experience of meaningful work for self-employed individuals
}

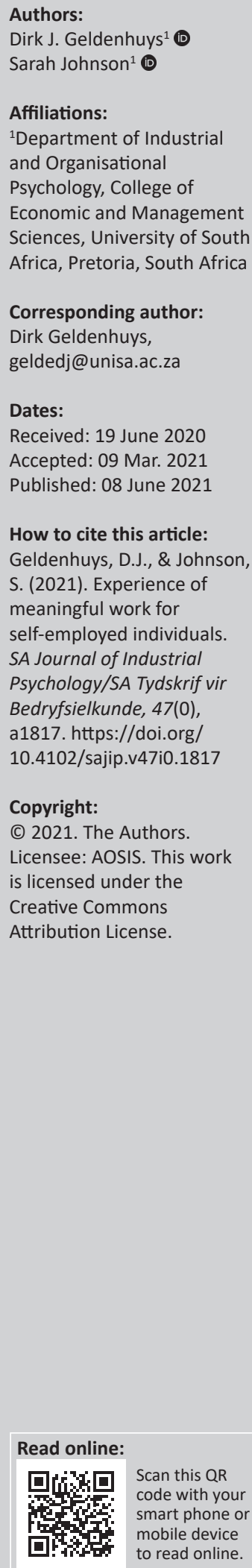

Orientation: This article is about the experience of meaningful work for self-employed individuals.

Research purpose: The purpose of this study was to explore how meaningful work is experienced by self-employed individuals.

Motivation for the study: Research tends to focus on meaningful work from either the formally employed individual or the organisational perspective, and very little research has included the perspective of self-employed individuals. The number of employed individuals considering self-employment, however, has increased since the outbreak of the coronavirus disease 2019 (COVID-19), which triggered a global recession that has resulted in a substantial number of job losses and questionable job security in various employment sectors.

Research design/approach and method: This was an interactive qualitative study to explore the experience of meaningful work for self-employed individuals. A social constructionist paradigm was adopted to study participants' attitudes towards their work, their values and feelings, what drives them and their perceptions of meaningful work. Data was collected and analysed from a purposive sample of five self-employed individuals.

Main findings: This study revealed that purpose is the primary driver in self-employed individuals' experience of meaningful work. Purpose facilitates feeling stimulated and creative expression. Cooperation encourages participation in meaningful work. Fulfilment is the primary outcome of self-employed individuals' experience of meaningful work.

Practical/managerial implications: Self-employed individuals can create opportunities for meaningful work. This study provides an understanding of the experience of self-employed individuals when they perform work they consider meaningful and the implications thereof.

Contribution/value-add: This study complemented existing literature on meaningful work and literature on self-employment, and may facilitate the experience of meaningfulness by the growing number of self-employed individuals.

Keywords: self-employed; meaningful work; interactive qualitative analysis; purpose; affinities.

\section{Introduction}

The literature on meaningful work remains highly fragmented (Lips-Wiersma \& Morris, 2009; Lysova, Allan, Dik, Duffy, \& Steger, 2019), despite efforts to combine it. Former empirical efforts indicated that instead of simply the extrinsic appeal of a salary, a clear intrinsic value for people is the meaning that they derive from their work (Jena, Bhattacharyya, \& Pradhan, 2019; Simonet \& Castille, 2020). It is no longer just about work being a means to an end, as people want their work to have meaning (Steger, Littman-Ovadia, Miller, Menger, \& Rothmann, 2012). The higher educational level, availability of improved opportunities and the heightened sense of curiosity to better understand one's life with regard to personal and professional contexts have attributed to the rising interest amongst contemporary researchers to study meaningfulness of work (Geldenhuys, Łaba, \& Venter, 2014; Jena et al., 2019).

Meaning is both an objective and a subjective concept (Reitinger, 2015). When a person performs work that is a best possible match for their interests, skills and values (Bunderson \& Thompson, 2009; Duffy, Allan, Autin, \& Bott, 2013; Haney-Loehlein, McKenna, Robie, Austin, \& Ecker, 2015; Willemse \& Deacon, 2015), they experience direction and a sense of purpose as well as the desire to be of service and personal fulfilment (Hall \& Chandler, 2005; Lips-Wiersma, Wright, \& Dik, 2016; Willemse \& Deacon, 2015). This serves as a source of a motivation to fulfil one's larger purpose and 
serve the greater good (Hunter, Dik, \& Banning, 2010; Willemse \& Deacon, 2015). Hall and Chandler (2005) noted that one of the deepest forms of satisfaction or psychological success takes place when a person experiences work as greater than merely a job or career. It arises from a strong perception of inner direction (Hall \& Chandler, 2005; Lips-Wiersma, 2002). Merely obtaining fulfilment in working or in the belief that one's work has an effect on society in one way or another (Hall \& Chandler, 2005) can therefore be regarded as essential to one's identity and life.

Meaningful work comprises over and above that what a person's work means to them (i.e. meaning of work) (Fouché, Rothmann, \& Van der Vyver, 2017; Steger et al., 2012). It is the all-consuming and meaningful fervour a person experiences towards a profession (Bunderson \& Thompson, 2009; Guo et al., 2014; Hall \& Chandler, 2005). A person will be more fulfilled when they can find meaning in their work (Burger, Roodt, \& Crous, 2013).

It is argued in this article that job losses in the formal sector because of the global pandemic since the outbreak of coronavirus disease 2019 (COVID-19) will lead to more educated individuals leaving the formal sector to become selfemployed. Research indicates that self-employed individuals have an appreciation of and commitment to hard work, perseverance, greater job satisfaction and a need for autonomy, achievement and meaningful work (Beutell, Schneer, \& Alstete, 2014; Gorgievski, Bakker, \& Schaufeli, 2010; Warr \& Inceoglu, 2018; Wolfe \& Patel, 2019). Although there has recently been an increased focus on the subjective characteristics of meaningful work (the experience of meaningful work), instead of the conditions from which meaningful work arises (Lips-Wiersma et al., 2016) and in spite of the amount of research on hand regarding meaningful work, the focal point has been on employed individuals. Self-employed individuals and employed individuals are argued to be members of two qualitatively diverse subcultures (Gorgievski et al., 2010), and it can therefore be deduced that the experience of meaningful work cannot be deemed equal across both groups. It is noted that when compared with employed individuals, selfemployed individuals have been found to be 'significantly higher on work-family synergy (WFS), in better mental health, earned higher incomes, [and] had more autonomy, flexibility, and learning opportunities on the job', and to be 'more satisfied with family life and life in general' (Beutell et al., 2014, p. 408).

Therefore, the experience of meaningful work by selfemployed individuals seems to be different from that of employed individuals. There is, however, limited information regarding how self-employed individuals experience meaningful work, as the research literature does not appear to be keeping up with the fast growth of the self-employment sector (Beutell et al., 2014; Perry, Penney, \& Witt, 2008).

\section{Research purpose}

Amidst a pandemic since the outbreak of COVID-19, which has triggered a global recession that has resulted in a substantial number of job losses and questionable job security in various employment sectors, there has been an increase in the number of employed individuals considering selfemployment. Self-employed individuals and employed individuals are argued to be members of two qualitatively diverse subcultures (Gorgievski et al., 2010); however, research tends to focus on only a few variables from either the formally employed individual or the organisational perspective, and very little research has included the perspective of selfemployed individuals, as the research literature does not appear to be keeping up with the fast growth of the selfemployment sector (Beutell et al., 2014; Perry et al., 2008). The purpose of this study was therefore to explore the experience of meaningful work by self-employed individuals.

\section{Trends from the research literature}

\section{Definition of meaningful work}

There are various ways in which meaningful work has been defined and operationalised (Allan, 2017). Pratt and Ashforth (2003), Allan (2017) and Lysova et al. (2019) differentiated between 'meaning' and 'meaningfulness'. They expressed that 'meaning' comprises people making sense of the work they perform, through the process of meaning-making, and may be considered as positive, negative or neutral (Lepisto \& Pratt, 2017; Lysova et al., 2019). 'Meaningfulness' or 'meaningful work', on the contrary, refers to the experience of as being especially significant and valuable to oneself and/or others and has positive valence (Allan, 2017; Lysova et al., 2019; Pratt \& Ashforth, 2003; Van Wingerden \& Van der Stoep, 2018). Meaningfulness therefore denotes a positive, subjective, personal experience concerning work (Bailey et al., 2019b). For the purposes of this article, meaningful work is generally referred to as work that is deemed personally significant and worthwhile. This relates to work that is considered linked to fulfilling one's purpose and as the uppermost form of subjective career success, and work that is significant to the nature of one's existence (Lepisto \& Pratt, 2017; Onça \& Bido, 2019; Rosso, Dekas, \& Wrzesniewski, 2010).

\section{Theories of meaningful work}

Chalofsky (2003) cited the works of Maslow (1943, 1954, 1970, 1971) as well as Herzberg (1959), McClelland (1965) and Alderfer (1972), who theorised that the fulfilment of needs thought to be intrinsic in all humans motivates people to take certain actions. These theorists suggested that as people's needs move from fundamental survival needs to higherorder needs, they become more inherent and reflective in nature. The higher-order needs are translated as values, working towards a greater cause, life purpose and meaningfulness (Chalofsky, 2003).

Following the conception of his hierarchy of needs, Maslow (1971, as cited in Chalofsky, 2003) began to explore the meaning of work. He held that people have the potential to reach what he termed self-actualisation, which is the process of expressing oneself to the highest possible degree in a way that is personally fulfilling and developing one's potential. It 
is not an end-state but an ongoing process of becoming (Chalofsky, 2003; Fairlie, 2011; Lieff, 2009). Also worth mentioning is the detailed discourse by Rogers (1961), Locke (1975) and Ackoff (1981), as summarised by Chalofsky (2003). Rogers (1961) believed that people find purpose when they experience freedom to just be themselves in an adaptable and changing way. According to Locke (1975), people strive to attain goals with the purpose of fulfilling their aspirations and emotions. Ackoff (1981) described meaning and purpose as progression towards an ideal that changes trivial existence into significant living (Chalofsky, 2003; Joseph \& Murphy, 2013).

Research on the meaning of work covers a broad terrain across numerous disciplines and has focussed on questions regarding where people find meaningfulness in their work, how different meanings are made of the same work, the personal and organisational implications of maintaining different beliefs about the meaning of work and how the meaning of work has changed over time and across cultures (Rosso et al., 2010). Researchers' interest in this subject has been powered by the extensiveness of personal and organisational effects correlated with perceptions of meaning and meaningfulness in work.

The subject of the meaning of work also appeals to researchers because it transcends hedonic perspectives of work behaviour to deeper considerations of purpose and significance and eudaimonic aspects of well-being (Rosso et al., 2010). Although the work one performs relates to both Maslow's level of self-actualisation and Alderfer's growth levels, and to a degree to Herzberg's motivators, the focal point is on carrying out one's purpose through the work itself; it is about working and growing as an ongoing process rather than about productivity or an end-state (Chalofsky, 2003).

The single most fundamental descriptor that defines one's sense of purpose is the need for meaningful work (Jaeger, 1994, as cited in Chalofsky, 2003). According to Chalofsky (2003), work is a recognised part of one's personal identity; it is that which brings about enjoyment, meaning and satisfaction to their lives. In this regard, three themes have emerged from research on meaningful work, namely the work itself, a sense of self and a sense of balance. These themes are reflected in the term 'integrated wholeness' (Svendsen, 1997, as cited in Chalofsky, 2003). They therefore overlap and are intertwined. Meaningful work requires the interaction of all these elements.

\section{Models and dimensions of meaningful work}

According to Lips-Wiersma and Wright (2012) and LipsWiersma et al. (2016), there are four dimensions of meaningful work, namely developing the inner self (inward and reflective), unity with others (a sense of shared values and belonging), service to others (contributing to others' wellbeing and making a difference) and expressing full potential (active and outward-directed). This framework portrays the tensions inherent in the pursuit for meaning, including the significance of meeting the needs of the self and of others as well as the need for being (reflection) and doing (action). These are inherent in meaningful work (Bailey et al., 2019; Lips-Wiersma \& Wright, 2012).

Furthermore, Rosso et al. (2010) proposed that meaningful work can be elucidated by using two psychological dimensions, which vary based on the direction of action (towards self or others) and the person's underlying motives (agency or communion). In their model, the self-other dimension indicates the target towards which the effort to create meaningfulness is directed (whether internal to the self or external). Work experiences that are oriented towards the self can be experienced as meaningful, as can experiences that are oriented towards others. However, the processes through which these sources are experienced as meaningful appear to be quite different, as they refer to perceptions of meaningful work. The agencycommunion dimension, in contrast, refers to the person's motives, where agency motives (seeking to create, assert or divide elements, as one would do when playing a musical instrument) are distinguished from communion motives (seeking to connect or unite elements, as in the case of evaluating one's life goals or rekindling past relationships). The processes of meaningfulness therefore differ as it refers to the extent to which experiences are perceived as internal or external to the self (Lysova et al., 2019; Rosso et al., 2010). Both the self-other and the agency-communion dimensions relate to human action, through the motive for and the target of the action, respectively. Action directed towards the self (internally) or others (externally) and with the intention of expressing agency or achieving communion therefore seems to be especially meaningful (Rosso et al., 2010).

It is believed that meaningful work resides at the intersection of these dimensions, which reveals four primary pathways by which meaningful work is created or sustained, namely individuation (self-agency), contribution (other-agency), self-connection (self-communion) and unification (othercommunion) (Rosso et al., 2010). Individuation represents the meaningfulness of actions that delineate and differentiate the self as valuable and worthy; contribution represents the meaningfulness of actions perceived as extensive and/or done in service of something larger than the self; selfconnection reflects the meaningfulness of actions that bring individuals more in alignment with how they see themselves; and unification represents the meaningfulness of actions that bring individuals into harmony with other people or principles (Rosso et al., 2010).

A third model, proposed by Steger and Dik (2010), maintains that meaning arises when one is able to make sense of one's experience (e.g. who they are, their place in the world), directly or indirectly contribute to the greater good and develop a sense of purpose (i.e. identify and pursue highly valued, overarching goals).

The focal point of the above theoretical models of meaningful work is on the individual experience of meaningful work and includes an individual's attempts to express the self or serve 
the greater good. They, however, do not entirely include the societal and organisational factors that affect an individual in work, and where some theories have addressed the one factor, they do not address the other. Although there are different job-level, organisational-level and societal-level sources that individuals utilise to find meaningfulness in their work, it is the fit between the individual and the environment that ensures a smooth course towards meaningful work (Lysova et al., 2019).

One theme that emerges from the dimensions of meaning is the concept of self-transcendence. This means that people appear to have a need to transform themselves (i.e. development) and the world around them (i.e. generativity), whilst progressing towards important end-states (i.e. purpose, achievement) (Fairlie, 2011). Meaningful work facilitates the achievement or preservation of one or more dimensions of meaning.

Meaningful work occurs at the intersection of where one is and what one does. It is evident from the body of research available on meaningful work (Kim \& Allan, 2019; Verleysen, Lambrechts, \& Van Acker, 2015) that there are various personal fundamental needs that, if manifested, can have a direct influence on an individual's perception of the meaning of their work and their experience of meaningful work. These personal fundamental needs include the need for a legacy, spiritual growth, autonomy, helping or serving others and creative expression.

\section{Outcomes of meaningful work}

The outcomes associated with work play a central role in people's lives and in society in general. Working and the outcomes thereof are considered by a large amount of people as being a major part of their lives, for several reasons, namely that it has an economic/instrumental aspect (i.e. work provides an income, which ensures one's livelihood and provides for one's material needs), and the commitment to work is perceived as part of human nature or needs (i.e. work provides the will to strive, learn, develop and accomplish, as well as to construct one's reality) (Sharabi, 2017).

Undeniably, the meaning of work has been revealed to influence some of the most important outcomes in organisational studies, such as motivation (Chalofsky, 2003; Van Wingerden \& Van der Stoep, 2018), work behaviour and engagement (Fairlie, 2011; Lips-Wiersma et al., 2016; Simonet \& Castille, 2020; Van der Walt, 2018), job satisfaction (Bailey et al., 2019; Fairlie, 2011; Lips-Wiersma et al., 2016; Simonet \& Castille, 2020), empowerment (Chalofsky, 2003; Jena et al., 2019), stress (Allan, Dexter, Kinsey, \& Parker, 2018; Jena et al., 2019; Simonet \& Castille, 2020; Wolfe \& Patel, 2019), career development (Jena et al., 2019; Lieff, 2009), individual performance (Jena et al., 2019; Sharabi, 2017; Van Wingerden \& Van der Stoep, 2018) and personal fulfilment (Jena et al., 2019).

Involvement in meaningful work has also been associated with higher levels of well-being, zest, an overall feeling of contributing to the greater good and a perception of the importance of work (Allan et al., 2018; Burger et al., 2013; Gazica \& Spector, 2015; Hagmaier \& Abele, 2015; Horvath, 2015; Janik \& Rothmann, 2015; Rosso et al., 2010; Willemse \& Deacon, 2015). Research indicates that work has a direct impact on an individual's physical and psychological health, and to be psychologically healthy an individual needs to feel that what he or she is doing is meaningful and serves a valuable purpose (Veltman, 2015). Meaningful work therefore improves mental health (Allan et al., 2018; Mulki \& Lassk, 2019) and is also an important contributor to an individual's physical health (Martela \& Steger, 2016; Veltman, 2015).

Thomas (2000, as cited in Chalofsky, 2003) captures what the research has confirmed, with his list of the four crucial inherent rewards of meaningful work, namely a sense of meaning and purpose, a sense of choice, a sense of competence and a sense of progress or moving towards accomplishment.

Meaningful work is therefore not limited to an individual's subjective perception, but it includes themes of human development. This includes self-actualising work (i.e. realising one's potential through work), realising one's purpose in life, values, goals and social impact (i.e. having an impact on people and things through work) (Fairlie, 2011; Lips-Wiersma et al., 2016). What is recognised as meaningful in the lives of many people is frequently directly linked to self and identity (Fairlie, 2011). However, sociological aspects have a definite contribution to an individual's experience of meaningful work (Allan, 2017; Fairlie, 2011; Lysova et al., 2019). The outcomes of meaningful work are therefore even broader than the work context, and they influence life in a holistic way.

\section{Research design}

Research approach

A social-constructionist approach was adopted, by using interactive qualitative analysis (IQA). Interactive qualitative analysis is a qualitative research methodology that provides a systemic, accountable and rigorous framework for qualitative inquiry. It is considered an apt design when researchers want to examine in what way phenomena are socially formulated, and whether they want to construct a theory of the research phenomenon that illustrates a systemic comprehension of the phenomenon (Northcutt \& McCoy, 2004). Interactive qualitative analysis entrusts the role of generating and interpreting data to the constituents, although the process is facilitated by the researcher (Bargate, 2014; Northcutt \& McCoy, 2004). According to Northcutt and McCoy (2004), IQA addresses power relations between participants and the researcher. Participants, or constituents, as referred to in IQA terminology, are involved in the generation, collection and analysis of their own data through various IQA protocols.

The ontological assumptions surrounding IQA directly address the dependence of power and knowledge positions between participants and the researcher (Northcutt \& McCoy, 
2004). A socially constructed ontology is supported by an IQA research design, and it recognises that several phenomena are social constructions filled with social meaning. Northcutt and McCoy (2004, p. 40) expound that in IQA the focus is on social systems, which are defined as 'systems in which human interpretation of meaning is involved'. According to Geldenhuys (2015), social constructionism is interested in the meanings attributed to things, or the so-called 'facts', and it focusses on the methods through which people come to their understanding of themselves and their world (Geldenhuys, 2015).

Although the ontological foundation of IQA is that of social constructionism, the epistemological foundation is social constructivist, as it acknowledges that people experience their world through the social construction of meaning. Both deduction and induction are deemed necessary to investigations of meaning (Northcutt \& McCoy, 2004, p. 16). Participants are therefore requested to induce categories of meaning (induction), then to define and refine these (induction and deduction) and, finally, to deductively examine the relationships of influence between the categories. These three stages of data analysis are consistent with the three formal categories of analysis of coding (i.e. emergent, axial and theoretical) (Northcutt \& McCoy, 2004). Geldenhuys (2015) asserts that the epistemological assumption of social constructionism is concerned with how knowledge can be formed, obtained and conveyed (i.e. what it means to 'know').

\section{Research strategy}

The research strategy selected for this study was a focus group, with subsequent individual semi-structured interviews. The focus group encouraged simultaneous collection and analysis of data, and through the affinities (themes) that emerged in the focus group the content of the individual semi-structured interviews was ascertained. The semi-structured interviews were utilised to corroborate the findings of the focus group (Northcutt \& McCoy, 2004) and facilitated data saturation for the purposes of this qualitative study because they provided the group-level processes with additional depth and individual experience (Fusch \& Ness, 2015).

\section{Research method}

\section{Research setting}

The research was conducted at the Titanium Boardroom at the Silverstar Centre in Krugersdorp. This was considered a neutral location, which allowed for and encouraged the voluntary participation of the constituents. The researchers were not directly associated with the organisation, and access to the boardroom was obtained at the researchers' own cost.

\section{Entrée and establishing researcher roles}

The location selected for the focus group was considered ideal because of the nature of the study (exploring the experience of meaningful work for self-employed individuals). It was therefore deemed appropriate to secure a location that allowed for and encouraged the voluntary participation of the constituents in a neutral setting.

The researcher's role in an IQA focus group is that of a facilitator, where the purpose is to allow constituents to reflect on their experience of the phenomenon being investigated. The role of the researcher as facilitator of the process minimises the researcher's power and influence over constituents during data analysis.

\section{Research participants and sampling methods}

A purposive sampling method was used to select participants, or constituents, as referred to in IQA terminology (Northcutt $\&$ McCoy, 2004). The participants in an IQA study are selected as representatives of a constituency, which means that they are considered as an expert on the phenomenon under investigation on account of their affiliation to a specific group (Northcutt \& McCoy, 2004).

Participants for this study were selected based on their selfemployed status, but they represent diverse backgrounds in terms of age, skills and occupation. Representivity in IQA refers to a participant having personal experience of the constructs being studied from a specific perspective as a result of their association to a specific group (Northcutt \& McCoy, 2004).

For the study, 21 self-employed individuals were identified and contacted to participate in the study. A total of nine selfemployed individuals agreed to participate in the study. Only five participants arrived for the focus group. One of the participants has been working in a self-employed capacity for 3 years and is involved in the agricultural sector. One of the participants has been working in a self-employed capacity for over 10 years and is involved in renovation and restoration projects of houses. The other participants had been working in a self-employed capacity for over 20 years, with one being involved in Internet hosting services and systems analysis, one being involved in photography, laser engraving and woodworking ventures and one being involved in several network marketing ventures. The participants' ages ranged between 25 and 55 years.

\section{Data collection methods}

In accordance with IQA protocol, the data were collected in two phases (Northcutt \& McCoy, 2004). The first phase involved a focus group and the construction of a visual representation. During the first phase, participants were requested to silently brainstorm the phenomenon being explored, so as to initiate reflection and generate ideas. The brainstorming process was driven by an issue statement to stimulate thoughts and feelings (Northcutt \& McCoy, 2004). The issue statement presented was 'When you think about your experience of meaningful work, what comes to mind?' Participants were requested to write down one thought or reflection per Post-it ${ }^{\circledR}$ note, and they were not limited regarding the number of thoughts they could generate 


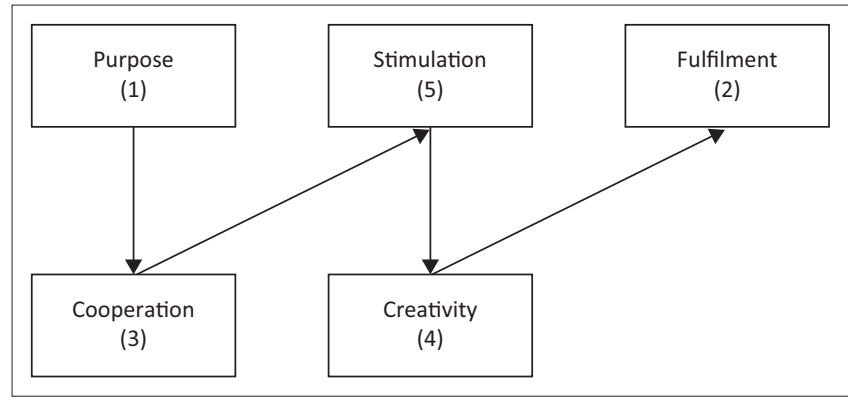

FIGURE 1: Uncluttered linear system influence diagram.

(Northcutt \& McCoy, 2004). The Post-it ${ }^{\circledR}$ notes were then stuck on a wall to enable the participants to reach a socially constructed, common meaning of each response and also to reduce any ambiguity associated with the meaning of the words or phrases on the Post-it ${ }^{\circledR}$ notes (Bargate, 2014; Northcutt \& McCoy, 2004).

The second phase of the study entailed the individual semistructured interviews, which were based on the affinities (themes) developed by the focus group. In IQA, the purpose of the individual semi-structured interviews is to provide analytical and interpretive depth to the system influence diagrams (SIDs). They do not denote a new phase in the collection of data but provide participants with an opportunity to reflect on what the phenomenon personally means to them (Northcutt \& McCoy, 2004). As a starting point for the purposes of the individual semi-structured interviews, the uncluttered linear SID (see Figure 1) was presented.

\section{Data recording}

The focus group and the individual semi-structured interviews were audio-recorded by using a digital voice recorder. As audio recordings are difficult to anonymise, this was only used for transcription purposes. The audio recordings have been saved on a password-protected computer. An audit trail was created as it refers to the IQA data analysis method, where every step and decision in the analysis of the data was recorded and accounted for (Northcutt \& McCoy, 2004).

\section{Strategies employed to ensure data quality and integrity}

According to Northcutt and McCoy (2004, p. 17), IQA is 'clearly favourable to theory, both from the point of view of inducing theory and of testing it', and it provides a systemic, accountable and rigorous framework for qualitative inquiry. Because of the fact that participants were involved in the thematic analysis, and by confirming themes with participants during the individual semi-structured interviews, this provided the ideal platform for triangulation (Northcutt \& McCoy, 2004). The researchers ensured that the findings came solely from the participants. An audit trail of traceable and transparent procedures was created, where the participants were actively involved in the process of data collection and analysis (Bargate, 2014). The researchers furthermore used a thick description to show that the findings of the study can be applicable to other contexts, circumstances and situations (Anney, 2014; Elo et al., 2014).

\section{Data analysis \\ Affinities}

After the meaning of the responses was clarified, the participants were invited to recognise themes or commonalities in the different responses. The purpose of this analysis was to cluster, or categorise, the cards according to 'as-yet-unarticulated, but nevertheless meaningful criteria' (Northcutt \& McCoy, 2004, pp. 97-98). By means of inductive coding, the data were categorised into thematically organised groups and to identify affinities, which was the point where categories and topics began to emerge (Northcutt \& McCoy, 2004, p. 98).

Affinities were described, refined and narrowed by means of group discussion, until every participant agreed that the meaning of the affinity was accurately reflected by the definition thereof. By means of deductive coding, the group then generated titles or headings that accurately described the meaning of each affinity. These titles, or headings, were documented on header notepads and were placed at the top of each vertical column. From the cards and the affinities generated, the researchers recorded a brief description representing the general content and meaning of each affinity, as collectively described by the group (Northcutt \& McCoy, 2004).

\section{Theoretical coding}

Interactive qualitative analysis is designed to determine the causal relationship between the affinities through theoretical coding. This is where participants establish what they perceive to be the cause-and-effect relationship (influences) between each of the affinities $(A \leftarrow B$ or $A \rightarrow B$ ) or the absence of a relationship between affinities $(\mathrm{A}<>\mathrm{B})$. (Northcutt \& McCoy, 2004, p. 149). Of importance to note is that participants are not assessing the strength of a relationship, but simply the existence and direction of a relationship (Human-Vogel \& Van Petegem, 2008).

The Pareto principle was used to determine which relationships to analyse from several potential causal relationships (Northcutt \& McCoy, 2004). It states that 20.0\% of the variables in the system will account for $80 \%$ of the total variation in outcomes (Northcutt \& McCoy, 2004, p. 158). In this study, the selected relationships reflected all those relationships up to $80.0 \%$.

Constructs were then sorted to identify the relative drivers (causes) and outcomes (effects) in the system (Human-Vogel \& Van Petegem, 2008; Northcutt \& McCoy, 2004). The primary driver (a significant cause) affects numerous other affinities but is not affected by other affinities. The secondary driver is a relative cause of or influence on affinities. The circulators/pivots take place when there are equal numbers 
of influences by and on other affinities. The primary outcome (a significant effect) is caused by numerous affinities, but does not affect others, whereas the secondary outcome reveals a relative effect (Northcutt \& McCoy, 2004). The results of the theoretical coding are presented in the group interrelationship diagram (IRD).

\section{System influence diagram}

In the final phase of the data analysis for the focus group, a SID is drawn to visually depict the entire system of the affinities and the relationships between them. The SID represents a summary of the underlying structure or mind map of the group. To identify the placement of the affinities in the SID, a tentative SID assignments chart was constructed.

As the SID is often too complex to be meaningful, redundant links are eliminated to obtain a simpler representation. This process, known as 'rationalisation' (Northcutt \& McCoy, 2004, p. 37), is carried out for comprehensiveness, complexity, parsimony or simplicity and visual interpretability.

The process of eliminating redundant links resulted in a clearer representation of the relationship between affinities and is depicted in an uncluttered SID. The uncluttered SID represents a mind map, consisting of only the minimum number of links needed to fully represent the underlying logic of the IRD (Northcutt \& McCoy, 2004). The uncluttered SID was modified to be represented in a more linear style, and it was used for the second phase of the IQA process, namely the individual semi-structured interviews.

\section{Reporting}

The key findings are detailed in the following section. The findings from the focus group are reported on, followed by the findings from the individual semi-structured interviews. The researchers utilised verbatim extracts from the focus group and the individual semi-structured interviews, and numbers have been assigned to the participants ('P1', 'P2', etc.) to ensure anonymity.

\section{Findings \\ Focus group}

The focus group generated five affinities, which participants used to generate a theory through inductive and deductive processes. The affinities are detailed in Table 1.

To construct the IRD, the affinities were assigned a comparative position within the system, by arranging them in descending order of delta, and thereby enabling the identification of drivers (causes) and outcomes (effects) within the system. The IRD is presented in Table 2.

The tentative SID assignments of the affinities are visually depicted in Table 3.

The resultant visual representation (SID) that was constructed is a depiction of the theory generated by the group (Northcutt
TABLE 1: Affinities generated by the focus group.

\begin{tabular}{ll}
\hline Name of the affinity & Meaning of the affinity \\
\hline 1. Purpose (P) & $\begin{array}{l}\text { Purpose is the motivation to do what one does and having a } \\
\text { set of core values that drive one to serve others. If there is } \\
\text { no purpose, one cannot do anything. Purpose motivates } \\
\text { everything else. }\end{array}$ \\
2. Fulfilment (F) & $\begin{array}{l}\text { Fulfilment is part of purpose, and it relates to finding } \\
\text { meaning in one's desires. }\end{array}$ \\
3. Cooperation (Coop) & $\begin{array}{l}\text { To get the end result, one needs cooperation from others. } \\
\text { One needs to serve to get cooperation, to get 'buy-in'. }\end{array}$ \\
4. Creativity (C) & $\begin{array}{l}\text { People are creative beings, and they have an innate desire } \\
\text { to be creative. Creativity relates to fulfilling a need, and it } \\
\text { stimulates a person for the next thing. }\end{array}$ \\
5. Stimulation (S) & \begin{tabular}{l} 
Stimulation is the seed that leads to the work being done. \\
\hline
\end{tabular}
\end{tabular}

TABLE 2: Interrelationship diagram with affinities in descending order of delta.

\begin{tabular}{lccccccccc}
\hline Affinities & No. & $\mathbf{1}$ & $\mathbf{2}$ & $\mathbf{3}$ & $\mathbf{4}$ & $\mathbf{5}$ & Out & In & $\boldsymbol{\Delta}$ \\
\hline Purpose (P) & 1 & & $\uparrow$ & $\uparrow$ & $\uparrow$ & $\uparrow$ & 4 & 0 & 4 \\
Cooperation (Coop) & 3 & $\leftarrow$ & $\uparrow$ & $\uparrow$ & $\uparrow$ & 3 & 1 & 2 \\
Stimulation (S) & 5 & $\leftarrow$ & $\leftarrow$ & $\uparrow$ & & 2 & 2 & 0 \\
Creativity (C) & 4 & $\leftarrow$ & $\leftarrow$ & $\leftarrow$ & 1 & 3 & -2 \\
Fulfilment (F) & 2 & $\leftarrow$ & $\leftarrow$ & $\leftarrow$ & 0 & 4 & -4 \\
\hline
\end{tabular}

TABLE 3: Tentative system influence diagram assignments.

\begin{tabular}{lll}
\hline No. & Affinities in descending order of delta & Tentative SID assignments \\
\hline 1 & Purpose (P) & Primary driver \\
3 & Cooperation (Coop) & Secondary driver \\
5 & Stimulation (S) & Circulator/pivot \\
4 & Creativity (C) & Secondary outcome \\
2 & Fulfilment (F) & Primary outcome \\
\hline
\end{tabular}

SID, system influence diagram.

\& McCoy, 2004), and it is provided as the uncluttered linear SID in Figure 1.

\section{Primary driver: Purpose}

Purpose is linked to meaningful work, and as visually demonstrated (see Figure 1), this was indicated as what drives the group to participate in meaningful work. Identified as the primary driver, 'purpose' is considered the 'fundamental cause', or 'source of influence', in the system (Northcutt \& McCoy, 2004, p. 32). As a significant cause, several other affinities are affected by purpose, but purpose is not affected by other affinities.

The participants linked this affinity to words such as 'ministry' and 'service'. They emphasised that purpose and core values and goals are an essential component of their experience of and participation in meaningful work. In this regard, P4 stated that 'goals is just breaking purpose into categories' (P4, systems analysis/web hosting/rife technology, November 2019), and that 'having a purpose motivates your serving (others)' (P4, systems analysis/web hosting/rife technology, November 2019). The participants agreed that one's purpose drives everything in one's life and is the primary motivator in what one does. In this regard, P1 stated that 'your purpose is innate in you. You can't change it' (P1, environmental solutions, November 2019). P2 agreed, stating that 'I do believe we all have this innate purpose; it's ingrained in us, it's in our DNA, it's built into us' (P2, network marketing, November 2019). 


\section{Secondary driver: Cooperation}

'Cooperation' was identified as the secondary driver. Secondary drivers are relative causes of or influences on affinities in the system and are identified when there are both 'outs' and 'ins', but there are a higher number of 'outs' than 'ins'.

There was a lengthy debate between the participants about this affinity. P5 stated the following:

'You have to get some kind of cooperation, or buy-in, before you are in a position to serve. Service would be your initial motivation, but you would need something that would motivate you to serve. So, if you were going to start a church, for instance, you would need to have some kind of congregation before you could start that church, and that would require engaging with people, bringing some sort of collaboration together, even if it was just 10 people. But I would need to create that first before I have a platform from which to serve.' (P5, team building and corporate events/ construction, November 2019)

P4 noted that 'actually, I guess you don't need cooperation, because, if you think about it, you can serve people without [cooperation], but you are still cooperating with them even if they're not cooperating with you' (P4, systems analysis / web hosting/rife technology, November 2019). P5 stated the following:

'It comes back to the primary motivation, [which is] "I wanted to serve. I wanted to make a difference. I wanted to show love and compassion, and all of that stuff", but in order to get the end result, I need to create cooperation.' (P5, team building and corporate events/construction, November 2019)

P1 argued, by using the example given by P5, that 'if your motivation is to start a church, you will start a church. You won't worry about whether you've got [a congregation]' (P1, environmental solutions, November 2019). To reach consensus, the group related instances where cooperation was required for them to perform their respective work and achieve their intended outcome, and they agreed that to get the end result, one would need cooperation from others.

\section{Circulator: Stimulation}

The circulator 'stimulation' had the same number of 'ins' and 'outs' and is considered both a cause of and an effect on other affinities.

The participants described stimulation as the seed that leads to the work being done, and they noted that purpose will stimulate a person to do what they are doing. Some participants felt, however, that stimulation is reciprocal to fulfilment. In this regard, P4 stated that if you have stimulation, you have fulfilment. [...] It's why you're doing what you are', but also noted that 'you need to be stimulated yourself before you can stimulate others' (P4, systems analysis/web hosting/rife technology, November 2019). P5 added that 'for self-stimulation, or for the stimulation of others, you would still need to have a launching pad'
(P5, team building and corporate events/construction, November 2019).

\section{Secondary outcome: Creativity}

The secondary outcome affinity was indicated as 'creativity'. A secondary outcome reveals a relative effect. It is recognised when there are both 'ins' and 'outs', but there are more 'ins' than 'outs'.

The participants felt that people are creative beings, and that they have an innate desire to be creative. Creativity relates to fulfilling a need, and it stimulates a person for the next thing. P4 described creativity as 'any action, because as soon as you use your brain, you're creating' (P4, systems analysis/web hosting/rife technology, November 2019). The group agreed, stating that being able to create something new and to change circumstances is important in what they do. They used words such as 'innovate', 'empower', 'educate', 'uplift', 'insight' and 'motivate' to describe the importance of creativity in their experience of meaningful work.

\section{Primary outcome: Fulfilment}

The primary outcome is recognised as the affinity in the system with many 'ins' but no 'outs'. It is a significant affect that is caused by many of the affinities, but does not affect others (Northcutt \& McCoy, 2004). The affinity identified as the primary outcome in this system was 'fulfilment'.

During the discussion on fulfilment, it was noted that 'the service side of doing what you're doing is because you have love and compassion for people, or you want to heal or make a difference, or build relationships' (P5, team building and corporate events/construction, November 2019). In response to this statement, it was noted that 'the motivation for it all is for fulfilment; fulfilment is the objective, and service is what is required to get there' (P4, systems analysis/web hosting/ rife technology, November 2019).

\section{Individual semi-structured interviews}

The participants who were interviewed were not surprised by the outcome of the SID, and they agreed with the conclusion that was drawn from the SID. When the participants were probed about their thoughts regarding how affinities were arranged in the SID, they reiterated the importance of purpose as the driving force of their experience of meaningful work. In this regard, P1 stated that purpose is 'something that is inherent in us that aligns with our values, our core values' (P1, environmental solutions, November 2019). P4 also stated that purpose 'represents our core values' (P4, systems analysis/web hosting/rife technology, November 2019). This view was shared by the other participants, and, in particular, P5 added the following:

'[Purpose is] the reason behind doing something, to obviously reach that end goal of satisfaction. Purpose could be defined from an individual point of view, as something that gives you purpose, or something that is the purpose of the company that 
you're working with or working for. So I think for me, it would be an understanding of it as an individual goal, something that I want to set out to achieve, and that, in turn, would give me the purpose and the drive to reach that point of satisfaction or achievement, whatever it is I've predetermined there.' (P5, team building and corporate events/construction, November 2019)

The participants further agreed with the primary outcome of the affinities, namely fulfilment. In this regard, P3 noted that she can see when a client is happy with the end result and added that:

'[F]or me that's fulfilling, because I know that I've done something in their life that makes a difference. [...] Meaningful work to me is when I make people feel better about themselves' (P3, photography/graphic design/laser cutting, November 2019)

P2 noted that for him, helping others to change their lives is fulfilling, as he has experienced both successes and failures in business. He explained the following:

'Although the initial [objective] is yes, we get involved because of finances, secondary to that, which eventually sort of becomes the primary aspect, is the personal development and the motivation and the growth of an individual, having been involved with that.' (P2, network marketing, November 2019)

P1 noted that fulfilment for her means 'doing something that makes a difference to somebody else. [...] I think fulfilment comes from doing something well and just making a difference in some small way. It doesn't have to be huge' (P1, environmental solutions, November 2019). P5 noted that 'fulfilment would be reaching that end goal, the thing we started out with' (P5, team building and corporate events/ construction, November 2019).

\section{Discussion}

The purpose of this study was to explore the experience of meaningful work for self-employed individuals. The study aimed to delve into not only how meaningful work is conceptualised, but to also develop an understanding of the experience of self-employed individuals when they perform work that they consider meaningful, as well as the implications thereof.

The study revealed that purpose is the primary driver of selfemployed individuals' experience of meaningful work, and it was found that they link it to one's core values. This is consistent with what is noted by Costin and Vignoles (2019), who mentioned that purpose is understood as a motivational dimension that organises and stimulates goals and manages behaviour. It is also noted from Martela and Steger (2016) that purpose means having a sense of core goals and direction in life. In this regard, Gaudry (2018) concluded that subjective emotions have physical outcomes, by motivating purposeful, goal-directed behaviour.

Other affinities that emerged from the study were cooperation, stimulation and creativity. These affinities were noted to contribute to self-employed individuals' experience of meaningful work. Research indicates that meaningfulness is experienced in cooperation, or working together, when mutual support and a sense of belonging and shared values are experienced (Lips-Wiersma et al., 2016). It is noted in this regard that collaboration, or working together, is inherently meaningful, as the action of doing something together establishes a connection and provides the experience of common purpose (Lips-Wiersma \& Morris, 2009). It was emphasised in the study that without the involvement of others, work is meaningless. Research also indicates that work that is more interesting or stimulating produces feelings of accomplishment, promotes helpfulness and contributes to people's lives, which is considered crucial for achieving meaningful work (Geldenhuys et al., 2014), and that work that provides mental stimulation, amongst other things, is conducive to flourishing, even outside of work (Veltman, 2015). It is further noted from Chalofsky (2003) that for work itself to be considered meaningful, it requires more autonomy, or independence, empowerment, flexibility, risk-taking, continuous learning and creativity. According to Jena et al. (2019), meaningful work fosters empowerment. It was also noted that people have a desire to 'make a difference and create a meaningful world or an inner wisdom and compassion' (Chalofsky, 2003, p. 75). This is consistent with what is noted by Csikszentmihalyi (1997), namely that people value the process of discovery and creating most of all. People have a desire to be creative (Antal, Debucquet, \& Frémeaux, 2018) and to express this creativity through their work.

The study concluded that fulfilment is the primary outcome of self-employed individuals' experience of meaningful work. Research indicates that fulfilment is important in meaningful work (Geldenhuys et al., 2014), and reciprocally that meaningful work is a source of personal fulfilment (Simonet \& Castille, 2020). Duffy, Allan and Bott (2012) noted in this regard that serving others in some capacity contributes to a sense of meaning, or purpose, and can be linked to fulfilment. This was confirmed in the focus group and the semi-structured interviews.

\section{Practical implications}

This study expands the existing research on meaningful work, but with the focus being on the experience of selfemployed individuals. Meaningful work has direct implications for an individual's ability to realise their potential, purpose, values and goals. To capitalise on the positive impact of meaningful work, self-employed individuals should continually strive to measure their work against their perceived purpose and goals. It was reiterated in the study that having a sense of purpose, which is inherent in every individual, is central to the experience of meaningful work and is linked to goals and values. Self-employed individuals are fortunate to be in a position where they can create opportunities for meaningful work, and in this regard, it would be of value for them to create a vision board, linked to their perceived purpose and goals, showing where they 
see themselves in future, as a means to drive them in their pursuit of fulfilment and self-actualisation. A vision board enables a person to portray their thoughts visually, and when this is coupled with emotion (feeling associated with achieving their purpose, or goals), this enables them to create belief in their ability to do so. If an individual feels they are living out their purpose, they will believe it, and belief results in an individual taking the necessary action to create their desired result. Discussions with other self-employed individuals could also provide one with an understanding and appreciation of the experience of other self-employed individuals, and it could possibly influence one's own experience of meaningful work in a positive way.

\section{Limitations}

Despite the contribution of this study in helping to understand the experience of meaningful work for self-employed individuals, there are some limitations that are worth mentioning. One of the possible limitations of this study may be the sample size of participants in the focus group. Although the results were similar amongst the participants, which enabled the researchers to reach data saturation, it is acknowledged that this study was restricted to a small number of participants.

\section{Recommendations for future research}

It is recommended that studies of a similar nature be carried out with a larger number of participants, to facilitate a more extensive understanding of the experience of meaningful work for self-employed individuals. It is also recommended that consideration be given to the difference in the experience of meaningful work between newly self-employed individuals and those who have been self-employed for a period of time. It would furthermore be useful to compare the experience of meaningful work for self-employed individuals with those who are not self-employed. Further studies could also include research on meaningful work as it refers to societal or cultural influences that drive interpretations of meaning.

\section{Acknowledgements Competing interests}

The authors declare that they have no financial or personal relationships that may have inappropriately influenced them in writing this article.

\section{Authors' contributions}

The research was compiled by S.J. and supervised by D.J.G.

\section{Ethical considerations}

Ethical clearance to conduct the study was obtained from the University of South Africa Research Ethics Review committee (ERC reference number: 2019_CEMS/IOP_024). The researchers were continuously cognisant of the Health Professions Council of South Africa's (HPCSA) 'Ethical
Principles and Guidelines' as well as the University of South Africa's 'Policy on Research Ethics'. All participants provided signed informed consent and voluntarily contributed to the study.

\section{Funding information}

This research received no specific grant from any funding agency in the public, commercial or not-for-profit sectors.

\section{Data availability}

Data sharing is not applicable to this article as no new data were created or analysed in this study.

\section{Disclaimer}

The views and opinions expressed in this article are those of the authors and do not reflect the official policy or position of any affiliated agency of the authors.

\section{References}

Ackoff, R.L. (1981). Creating the corporate future: Plan or be planned for. New York: Wiley.

Allan, B.A. (2017). Task significance and meaningful work: A longitudinal study. Journa of Vocational Behavior, 102, 174-182. https://doi.org/10.1016/j.jvb.2017.07.011

Allan, B.A., Dexter, C., Kinsey, R., \& Parker, S. (2018). Meaningful work and mental health: Job satisfaction as a moderator. Journal of Mental Health, 27(1), 38-44. https://doi.org/10.1080/09638237.2016.1244718

Anney, V.N. (2014). Ensuring the quality of the findings of qualitative research: Looking at trustworthiness criteria. Journal of Emerging Trends in Educational Research and Policy Studies, 5(2), 272-281. https://doi.org/10.3109/08941939.2012.723954

Antal, A.B., Debucquet, G., \& Frémeaux, S. (2018). Meaningful work and artistic interventions in organizations: Conceptual development and empirical exploration. Journal of Business Research, 85, 375-385. https://doi.org/10.1016/j. jbusres.2017.10.015

Bailey, C., Lips-Wiersma, M., Madden, A., Yeoman, R., Thompson, M., \& Chalofsky, N. (2019a). The five paradoxes of meaningful work: Introduction to the special issue 'Meaningful work: Prospects for the 21st century'. Journal of Management Studies, 56(3), 481-499. https://doi.org/10.1111/joms.12422

Bailey, C., Yeoman, R., Madden, A., Thompson, M., \& Kerridge, G. (2019b). A review of the empirical literature on meaningful work: Progress and research agenda. Human Resource Development Review, 18(1), 83-113. https://doi. org/10.1177/1534484318804653

Bargate, K. (2014). Interactive qualitative analysis - A novel methodology for qualitative research. Mediterranean Journal of Social Sciences, 5(20), 11-19. https://doi.org/10.5901/mjss.2014.v5n20p11

Beutell, N.J., Schneer, J.A., \& Alstete, J.W. (2014). Comparing self-employment aspirants with the presently self-employed. Journal of Small Business \& Entrepreneurship, 27(5), 407-425. https://doi.org/10.1080/08276331.2015.1071006

Bunderson, J.S., \& Thompson, J.A. (2009). The call of the wild: Zookeepers, callings, and the double-edged sword of deeply meaningful work. Administrative Science Quarterly, 54(1), 32-57. https://doi.org/10.2189/asqu.52.3.351

Burger, D.H., Roodt, G., \& Crous, F. (2013). Exploring a model for finding meaning in the changing world of work (Part 3: Meaning as framing context). SA Journal of Industrial Psychology, 39(2), 1-10. https://doi.org/10.4102/sajip.v39i2.1022

Chalofsky, N. (2003). An emerging construct for meaningful work. Human Resource Development International, 6(1), 69-83. https://doi. org/10.1080/1367886022000016785

Costin, V., \& Vignoles, V.L. (2019). Meaning is about mattering: Evaluating coherence, purpose, and existential mattering as precursors of meaning in life judgments. Journal of Personality and Social Psychology, 118(4), 864-884. https://doi. org/10.1037/pspp0000225

Csikszentmihalyi, M. (1997). Creativity: Flow and the psychology of discovery and invention. New York, NY: HarperCollins.

Duffy, R.D., Allan, B.A., Autin, K.L., \& Bott, E.M. (2013). Calling and life satisfaction: It's not about having it, it's about living it. Journal of Counseling Psychology, 60(1), 42-52. https://doi.org/10.1037/a0030635

Duffy, R.D., Allan, B.A., \& Bott, E.M. (2012). Calling and life satisfaction among undergraduate students: Investigating mediators and moderators. Journal of Happiness Studies, 13(3), 469-479. https://doi.org/10.1007/s10902-011-9274-6

Elo, S., Kääriäinen, M., Kanste, O., Pölkki, T., Utriainen, K., \& Kyngäs, H. (2014). Qualitative content analysis: A focus on trustworthiness. SAGE Open, 4, 1-10. https://doi.org/10.1177/2158244014522633 
Fairlie, P. (2011). Meaningful work, employee engagement, and other key employee outcomes. Advances in Developing Human Resources, 13(4), 508-525. https:// outcomes. Advances in Developing

Fouché, E., Rothmann, S., \& Van der Vyver, C. (2017). Antecedents and outcomes of meaningful work among school teachers. SA Journal of Industrial Psychology, 43(1), 1-10. https://doi.org/10.4102/sajip.v43i0.1398

Fusch, P.I., \& Ness, L.R. (2015). Are we there yet? Data saturation in qualitative research. The Qualitative Report, 20(9), 1408-1416. https://doi.org/10. 46743/2160-3715/2015.2281

Gaudry, J.D. (2018). Liking what's good for you: Evolution, subjectivity and purpose. Cosmos and History: The Journal of Natural and Social Philosophy, 14(3), 359-375. Retrieved from https://www.cosmosandhistory.org

Gazica, M.W., \& Spector, P.E. (2015). A comparison of individuals with unanswered callings to those with no calling at all. Journal of Vocational Behavior, 91, 1-10. callings to those with no calling at all. Journa
https://doi.org/10.1016/j.jvb.2015.08.008

Geldenhuys, D.J. (2015). Social constructionism and relational practices as a paradigm for organisational psychology in the South African context. SA Journal of Industria Psychology, 41(1), 1-10. https://doi.org/10.4102/sajip.v41i1.1225

Geldenhuys, M., Łaba, K., \& Venter, C.M. (2014). Meaningful work, work engagement and organisational commitment. SA Journal of Industrial Psychology, 4O(1), 1-10. https://doi.org/10.4102/sajip.v40i1.1098

Gorgievski, M.J., Bakker, A.B., \& Schaufeli, W.B. (2010). Work engagement and workaholism: Comparing the self-employed and salaried employees. The Journal of Positive Psychology, 5(1), 83-96. https://doi.org/10.1080/17439760903509606

Guo, Y., Guan, Y., Yang, X., Xu, J., Zhou, X., She, Z., ... Fu, M. (2014). Career adaptability, calling and the professional competence of social work students in China: A career
construction perspective. Journal of Vocational Behavior, 85(3), 394-402. https:// construction perspective. Journal of
doi.org/10.1016/j.jvb.2014.09.001

Hagmaier, T., \& Abele, A.E. (2015). When reality meets ideal: Investigating the relation between calling and life satisfaction. Journal of Career Assessment, 23(3), 367-382. https://doi.org/10.1177/1069072714547164

Hall, D.T., \& Chandler, D.E. (2005). Psychological success: When the career is a calling Journal of Organizational Behavior, 26(2), 155-176. https://doi.org/10.1002/job.301

Haney-Loehlein, D.M., McKenna, R.B., Robie, C., Austin, K., \& Ecker, D. (2015). The power of perceived experience: Events that shape work as a calling. The Career Development Quarterly, 63(1), 16-30. https://doi.org/10.1002/j.2161 0045.2015.00092.x

Horvath, M. (2015). Predicting work outcomes from religiosity and perceived calling. The Career Development Quarterly, 63(2), 141-155. https://doi.org/10.1002/ The Career

Human-Vogel, S., \& Van Petegem, P. (2008). Causal judgments of positive mood in relation to self-regulation: A case study with Flemish students. Contemporary Educationa Psychology, 33(4), 451-485. https://doi.org/10.1016/j.cedpsych.2008.02.002

Hunter, I., Dik, B.J., \& Banning, J.H. (2010). College students' perceptions of calling in work and life: A qualitative analysis. Journal of Vocational Behavior, 76(2), 178-186. https://doi.org/10.1016/j.jvb.2009.10.008

Janik, M., \& Rothmann, S. (2015). Meaningful work and secondary school teachers' intention to leave. South African Journal of Education, 35(2), 1-13. https://doi. org/10.15700/saje.v35n2a1008

Jena, L.K., Bhattacharyya, P., \& Pradhan, S. (2019). Am I empowered through meaningful work? The moderating role of perceived flexibility in connecting meaningul work? The moderating role of perceived flexibility in connecting meaningful work and psychological empowerment. IIMB N
31(3), 298-308. https://doi.org/10.1016/j.iimb.2019.03.010

Joseph, S., \& Murphy, D. (2013). Person-centered approach, positive psychology, and relational helping: Building bridges. Journal of Humanistic Psychology, 53(1), 26-51. https://doi.org/10.1177/0022167812436426

Kim, T., \& Allan, B.A. (2019). Underemployment and meaningful work: The role of psychological needs. Journal of Career Assessment, 28(1), 76-90. https://doi. org/10.1177/1069072718824004

Lepisto, D.A., \& Pratt, M.G. (2017). Meaningful work as realization and justification: Toward a dual conceptualization. Organizational Psychology Review, 7(2), 99-121. https://doi.org/10.1177/2041386616630039

Lieff, S.J. (2009). Perspective: The missing link in academic career planning and development: Pursuit of meaningful and aligned work. Academic Medicine, 84(10), 1383-1388. https://doi.org/10.1097/ACM.0b013e3181b6bd54

Lips-Wiersma, M. (2002). The influence of spiritual 'meaning-making' on career behavior. Journal of Management Development, 21(7), 497-520. https://doi. org/10.1108/02621710210434638

Lips-Wiersma, M., \& Morris, L. (2009). Discriminating between 'meaningful work' and the 'management of meaning'. Journal of Business Ethics, 88(3), 491-511. https:// doi.org/10.1007/s10551-009-0118-9

Lips-Wiersma, M., \& Wright, S. (2012). Measuring the meaning of meaningful work: Development and validation of the comprehensive meaningful work scale (CMWS). Group \& Organization Management, 37(5), 655-685. https://doi. org/10.1177/1059601112461578
Lips-Wiersma, M., Wright, S., \& Dik, B. (2016). Meaningful work: Differences among blue-, pink-, and white-collar occupations. Career Development International, 21(5), 534-551. https://doi.org/10.1108/CDI-04-2016-0052

Locke, E.A. (1975). Personnel attitudes and motivation. Annual Review of Psychology, 26, 457-480. https://doi.org/10.1146/annurev.ps.26.020175.002325

Lysova, E.I., Allan, B.A., Dik, B.J., Duffy, R.D., \& Steger, M.F. (2019). Fostering meaningful work in organizations: A multi-level review and integration. Journal of Vocational Behavior, 110(13), 374-389. https://doi.org/10.1016/j.jvb.2018.07.004

Martela, F., \& Steger, M.F. (2016). The three meanings of meaning in life: Distinguishing coherence, purpose, and significance. The Journal of Positive Psychology, 11(5), 531-545. https://doi.org/10.1080/17439760.2015.1137623

Mulki, J., \& Lassk, F.G. (2019). Joint impact of ethical climate and external work locus of control on job meaningfulness. Journal of Business Research, 99, 46-56. https://doi.org/10.1016/j.jbusres.2019.02.007

Northcutt, N., \& McCoy, D. (2004). Interactive qualitative analysis: A systems method for qualitative research. London: Sage.

Onça, S.S., \& Bido, D.S. (2019). Antecedents and consequences of meaningful work. Revista de Administração Mackenzie, 20(2), e190096. https://doi. org/10.1590/1678-6971/eramg190096

Perry, S.J., Penney, L.M., \& Witt, L.A. (2008). Coping with the constraints of selfemployment: A person-situation model of entrepreneurial burnout. Academy of Management Proceedings, 1, 1-6. https://doi.org/10.5465/ambpp.2008. 33636328

Pratt, M.G., \& Ashforth, B.E. (2003). Fostering meaningfulness in working and at work. In K.S. Cameron, J.E. Dutton, \& R.E. Quinn (Eds.), Positive organizational scholarship: Foundations of a new discipline (pp. 309-327). San Francisco, CA: Berrett-Koehler.

Reitinger, C. (2015). Viktor Frankl's logotherapy from a philosophical point of view. Existential Analysis, 26(2), 344-358.

Rogers, C.R. (1961). On becoming a person. Boston, MA: Houghton Mifflin.

Rosso, B.D., Dekas, K.H., \& Wrzesniewski, A. (2010). On the meaning of work: A theoretical integration and review. Research in Organizational Behavior, 30 , 91-127. https://doi.org/10.1016/j.riob.2010.09.001

Sharabi, M. (2017). The meaning of work dimensions according to organizational status: Does gender matter? Employee Relations, 39(5), 643-659. https://do org/10.1108/ER-04-2016-0087

Simonet, D.V., \& Castille, C.M. (2020). The search for meaningful work: A network analysis of personality and the job characteristics model. Personality and Individual Differences, 152, 109569. https://doi.org/10.1016/j. paid.2019.109569

Steger, M.F., \& Dik, B.J. (2010). Work as meaning: Individual and organizational benefits of engaging in meaningful work. In N. Garcea, S. Harrington, \& P. Alex Linley (Eds.). Oxford handbook of positive psychology and work (pp. 131-142). New York, NY: Oxford University Press. https://doi.org/10.1093/ oxfordhb/9780195335446.013.0011

Steger, M.F., Littman-Ovadia, H., Miller, M., Menger, L., \& Rothmann, S. (2012) Engaging in work even when it is meaningless: Positive affective disposition and meaningful work interact in relation to work engagement. Journal of Career Assessment, 21(2), 348-361. https://doi.org/10.1177/10690 72712471517

Van der Walt, F. (2018). Workplace spirituality, work engagement and thriving at work. SA Journal of Industrial Psychology, 44(0), 1-10. https://doi.org/10.4102/sajip. v44i0.1457

Van Wingerden, J., \& Van der Stoep, J. (2018). The motivational potential of meaningful work: Relationships with strengths use, work engagement, and performance. PLoS One, 13(6), e0197599. https://doi.org/10.1371/journal. pone.0197599

Veltman, A. (2015). Is meaningful work available to all people? Philosophy \& Socia Criticism, 41(7), 725-747. https://doi.org/10.1177/0191453714556692

Verleysen, B., Lambrechts, F., \& Van Acker, F. (2015). Building psychological capital with appreciative inquiry: Investigating the mediating role of basic psychological need satisfaction. The Journal of Applied Behavioral Science, 51(1), 10-35. https:// doi.org/10.1177/0021886314540209

Warr, P., \& Inceoglu, I. (2018). Work orientations, well-being and job content of selfemployed and employed professionals. Work, Employment and Society, 32(2) 292-311. https://doi.org/10.1177/0950017017717684

Willemse, M., \& Deacon, E. (2015). Experiencing a sense of calling: The influence of meaningful work on teachers' work attitudes. SA Journal of Industrial Psychology, 41(1), 1-9. https://doi.org/10.4102/sajip.v41i1.1274

Wolfe, M.T., \& Patel, P.C. (2019). Labor of love? The influence of work-conditions among self-employed and work stress. Journal of Business Venturing Insights, 11, e00118. https://doi.org/10.1016/j.jbvi.2019.e00118 